\title{
Younger age as a prognostic indicator in breast cancer: A cohort study
}

\author{
Elrasheid AH Kheirelseid ${ }^{1}$, Jennifer ME Boggs', Catherine Curran' ${ }^{1}$, Ronan W Glynn', Cara Dooley ${ }^{2}$, Karl J Sweeney ${ }^{1}$ \\ and Michael J Kerin ${ }^{1 *}$
}

\begin{abstract}
Background: The debate continues as to whether younger women who present with breast cancer have a more aggressive form of disease and a worse prognosis. The objectives of this study were to determine the incidence of breast cancer in women under 40 years old and to analyse the clinicopathological characteristics and outcome compared to an older patient cohort.
\end{abstract}

Methods: Data was acquired from a review of charts and the prospectively reviewed GUH Department of Surgery database. Included in the study were 276 women diagnosed with breast cancer under the age of forty and 2869 women over forty. For survival analysis each women less than 40 was matched with two women over forty for both disease stage and grade.

Results: The proportion of women diagnosed with breast cancer under the age of forty in our cohort was $8.8 \%$. In comparison to their older counterparts, those under forty had a higher tumour grade $(p=0.044)$ and stage $(p=$ 0.046), a lower incidence of lobular tumours ( $<<0.001)$, higher estrogen receptor negativity $(p<0.001)$ and higher HER2 over-expression ( $p=0.002)$; there was no statistical difference as regards tumour size $(p=0.477)$. There was no significant difference in overall survival (OS) for both groups; and factors like tumour size $(p=0.026)$, invasion ( $p$ $=0.026)$ and histological type $(p=0.027), P R(p=0.031)$ and HER2 $(p=0.002)$ status and treatment received were independent predictors of OS

Conclusion: Breast cancer in younger women has distinct histopathological characteristics; however, this does not result in a reduced survival in this population.

\section{Background}

Breast cancer accounts for approximately $23 \%$ of all female malignancies, and its incidence is increasing, especially in the developed countries [1]. In young women, the incidence of the disease is low $(<17$ cases per 100,000 women or $<6 \%$ of all breast cancers among women of any age) [2,3]; however, accumulating evidence suggests that breast cancer in this age group is more aggressive and associated with poor outcome than in their older counterparts [4-6]

Although some reports have identified young age at diagnosis as an adverse prognostic indicator [7], this could be ascribed to a combination of factors, including delayed presentation, advanced disease stage and

\footnotetext{
* Correspondence: michael.kerin@nuigalway.ie

'Department of Surgery, National University of Ireland, Galway, Ireland

Full list of author information is available at the end of the article
}

unfavorable tumour characteristics [8,9]. Furthermore, the annual risk of recurrence appears to be constant throughout life, therefore the younger the age at diagnosis, the higher the accumulated lifetime risk of recurrence [10].

The objectives of this study were to determine the incidence of primary operable breast cancer in women under 40 years old and to analyse the clinicopathological characteristics and outcomes in this group of patients compared to those over forty.

\section{Methods \\ Patient cohort}

Data was acquired and collated from the prospectively reviewed Galway University hospital, Department of Surgery breast cancer database from 1989 through to 2009. Ethical approval for this database, and therefore any study that could arise from it, was granted by the

\section{() Biomed Central}


Clinical Research Ethics Committee, Galway University Hospitals and written consent was obtained from each of the patients before have their clinical data was recorded and then updated. The resulting data was further queried for cases under the age of 40 years. All patients were treated according to local protocols and followed three monthly for one year, 6 monthly for two years and then annually. Male patients and women who developed bilateral breast tumour were excluded from the study.

Data collected included patient demographics and year of presentation, tumour size, grade, stage, histological type, extent of tumour invasion and lymph node involvement and the presence or absence of local or distant metastasis. Estrogen (ER), progesterone (PR) and HER$2 /$ neu receptor status was also noted where data was available, as was local therapy and the use of hormonal therapy, chemotherapy and radiotherapy.

Prior to the advent of Tamoxifen use in the late 1980 s, bilateral prophylactic oopherectomy was performed routinely in premenopausal women with breast cancer. We used this group of patients to evaluate the impact of ovarian ablation on survival of young women with breast cancer.

The SPSS ${ }^{\circledR} 17.0$ software package (SPSS Inc., Chicago, IL, USA) was used for statistical analysis. Mann-Whitney $\mathrm{U}$ and t-tests were used, as appropriate, for comparison of continuous variables and the Chi-square test was employed for analysis of categorical variables. All tests were two sided and a result was considered significant if the calculated $P$ value was $<0.05$.

For survival analysis, each woman less than 40 was matched to the two closest controls (women over forty) for both disease stage and grade using a Malanhobis distance based on ranks, and the matching was carried out using the Optmatch package $[11,12]$. Survival distributions were analyzed using the Kaplan-Meier method. The statistical significance of differences in survival between groups was determined by log rank. Multivariate analysis was done using Cox regression, while logistic regression was employed for categorical data.

\section{Results}

There were 2869 cases of breast cancer identified in the 20 -year study period. The number of women diagnosed with breast cancer under the age of forty in the database was $276(8.8 \%)$ (Table 1). No significant difference in the size of the tumour at time of diagnosis was noted between the two groups $(\mathrm{p}=0.477)$. Younger women were more likely to present with grade 3 disease (36.7\% vs. 29.3, $p=0.044$ ) and women older than 40 years of age were more frequently diagnosed with invasive lobular carcinoma than younger women $(15.2 \%$ vs. $7.55, p<$ 0.001 ). Although the most common presenting stages
Table 1 Characteristics of breast cancer in less than $\mathbf{4 0}$ yrs women compared to more than $\mathbf{4 0}$ yrs group

\begin{tabular}{|c|c|c|c|}
\hline Variable & $\begin{array}{l}\text { Less than } 40 \\
(n=276)\end{array}$ & $\begin{array}{c}\text { More than } 40 \\
(\mathrm{~N}=2869)\end{array}$ & $P$ Value \\
\hline Age in yrs (SD) $\#$ & & & $<0.001^{*}$ \\
\hline Mean & $35.81(3.92)$ & $60.08(12.22)$ & \\
\hline Median (range) & $37(20-40)$ & $59(41-96)$ & \\
\hline Tumour size $(\mathrm{mm})^{\#}$ & & & 0.477 \\
\hline Mean & 21.49 & 22.74 & \\
\hline Median (range) & $20(1-120)$ & $20(1-160)$ & \\
\hline Tumour grade & & & $0.044^{*}$ \\
\hline Grade 0 & $69(27 \%)$ & $697(26.47 \%)$ & \\
\hline Grade 1 & $23(9 \%)$ & $262(9.9 \%)$ & \\
\hline Grade 2 & 70 (27.3\%) & 912 (34.5\%) & \\
\hline Grade 3 & 94 (36.7\%) & 774 (29.3\%) & \\
\hline Histology Type & & & $<0.001^{*}$ \\
\hline Ductal & $178(74.2 \%)$ & 1768 (72.8\%) & \\
\hline Lobular & $18(7.5 \%)$ & $368(15.2 \%)$ & \\
\hline Others & $44(18.3 \%)$ & $291(12 \%)$ & \\
\hline Tumour stage & & & $0.046^{*}$ \\
\hline 0 & $17(7.4 \%)$ & $210(9.2 \%)$ & \\
\hline I & $66(28.6 \%)$ & $538(23.6 \%)$ & \\
\hline$\|$ & $93(40.3 \%)$ & $850(37.3 \%)$ & \\
\hline III & 46 (19.9\%) & 477 (20.9\%) & \\
\hline IV & $9(3.9 \%)$ & $202(8.9 \%)$ & \\
\hline ER status & & & $<0.001^{*}$ \\
\hline Positive & $123(58.3 \%)$ & $1629(74.5 \%)$ & \\
\hline Negative & $88(41.7 \%)$ & $559(25.5 \%)$ & \\
\hline PR status & & & 0.319 \\
\hline Positive & $102(70.3 \%)$ & $1142(72.5 \%)$ & \\
\hline Negative & $43(29.7 \%)$ & $433(27.5 \%)$ & \\
\hline Her-2 status & & & $0.002^{*}$ \\
\hline Positive & $34(30.6 \%)$ & $213(18.6 \%)$ & \\
\hline Negative & 77 (69.4\%) & 935 (81.4\%) & \\
\hline Surgical treatment & & & $<0.001^{*}$ \\
\hline Mastectomy & 192 (75.9\%) & 1647 (61.9\%) & \\
\hline BCS & $61(24.1 \%)$ & $1012(38.1 \%)$ & \\
\hline Adjuvant hormonal therapy & & & $0.005^{*}$ \\
\hline Yes & $184(86.4 \%)$ & 2924 (92.4\%) & \\
\hline No & $29(13.6 \%)$ & 159(7.6\%) & \\
\hline Adjuvant chemotherapy & & & $0.021^{*}$ \\
\hline Yes & $109(46.2 \%)$ & $866(38.4 \%)$ & \\
\hline No & $127(53.8 \%)$ & $1389(61.6 \%)$ & \\
\hline Adjuvant radiotherapy & & & 0.778 \\
\hline Yes & $135(59.2 \%)$ & $1234(58 \%)$ & \\
\hline No & 93 (40.8\%) & 892 (42\%) & \\
\hline
\end{tabular}

\# Mann-Whitney u test, ER = Estrogens receptor, PR = Progesterone receptor

were similar in both groups, women less than 40 years of age were more likely to present at stage II, whereas women older than 40 years were more likely to present at an earlier stage $(p=0.046)$. 


\section{Tumour biology}

There were significant differences in ER status $(\mathrm{p}<$ $0.001)$ and HER2/neu status ( $\mathrm{p}=0.002)$. Approximately $42 \%$ of tumours in women less than 40 years of age were ER negative and $30.6 \%$ were $H E R 2 /$ neu positive; this compared with $25.5 \%$ and $18.6 \%$ in women over 40 , respectively. There were no differences according to PR status $(\mathrm{p}=0.319)$.

\section{Management of breast cancer in young women in our institution}

Excepting adjuvant radiotherapy, a significant trend towards more aggressive management was noted in the younger women cohort. They received both mastectomy (75.9\% vs. 61.9\%, $p<0.001$ ) and adjuvant chemotherapy (46.2\% vs. 38.4\%, $p=0.021$ ) more frequently than older women independent of disease stage. However; the difference in adjuvant chemotherapy noted between the two groups might be due to the large number of women $>60$ years in age (only 302 of the 1278 women over 60 years old received chemotherapy). On the other hand, women older than 40 years more frequently receive hormonal therapy (92.4 vs.86.4\%, $p=0.005$ ). About 159 women in the more than 40 years old group $(7.6 \%)$ opted out of the hormonal therapy due to intolerable side effects.

\section{Survival analysis}

Each of the younger breast cancer patients $(n=276)$ was matched for stage and grade to two older control patients $(n=552)$. Moreover, all the patients involved in the study were of the same ethnic origin. Median (interquartile range) follow-up was 194 (128-260) months for both groups.

No significant difference in disease free survival (DFS) was identified comparing the two groups using multivariate Cox regression analysis $(\mathrm{p}=0.150)$. Factors like nodal status ( $\mathrm{p}=0.012$ ), adjuvant hormonal therapy ( $\mathrm{p}$ $=0.047)$ and adjuvant chemotherapy $(\mathrm{p}=0.015)$ emerged as independent predictors of disease recurrence. Furthermore, we compared the local recurrence rates (LR) in less than 40 years group based on the surgical treatment they received. No significant difference in LR was determined comparing those who underwent mastectomy to those who had breast conserving surgery (BCS) using both univariate and multivariate analysis (Figure 1). The median local recurrence-free survival for women underwent mastectomy was 102 (76-127) months compared to 152 (19-284) months in the BCS group

Overall survival was calculated as the number of months from the diagnosis of the tumour to death or last followup. The median survival for women less than 40 years of age was 243 (88-300) months while that for the older

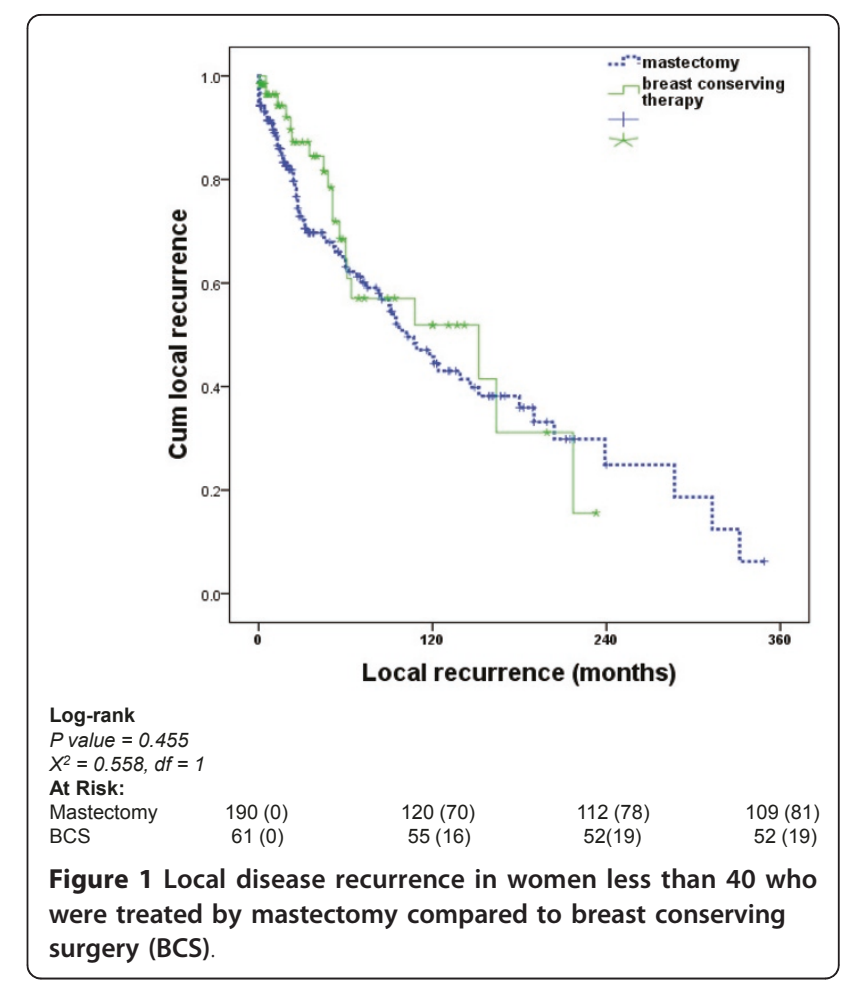

cohort was 299 (75-329) months. No significant difference in overall survival (OS) was noted when comparing the two groups (Figure 2). On Cox regression analysis, tumour size $(\mathrm{p}=0.048)$, stage $(\mathrm{p}=0.018)$ and $\mathrm{PR}$ status $(\mathrm{p}=$

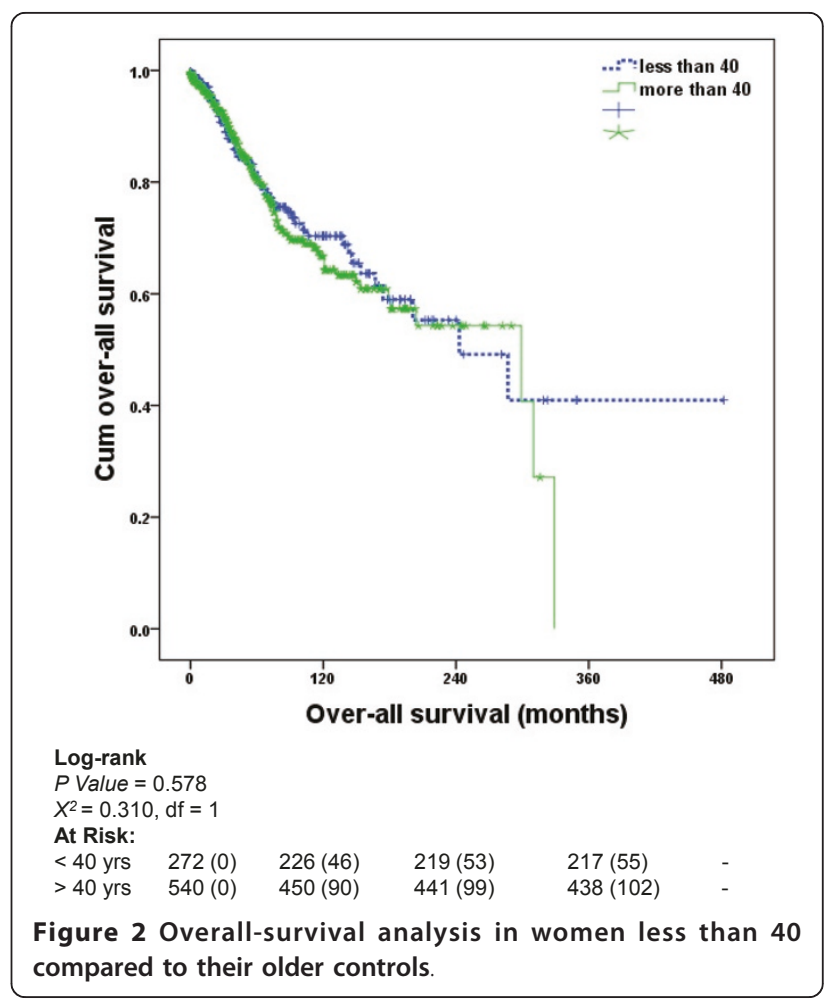


0.020) were independent predictors of survival. After adjustment for these variables, the OS in both groups did not differ significantly ( $\mathrm{p}=0.587$ ) (table 2$)$.

In order to address the effect of bilateral prophylactic oopherectomy, we compared the overall survival for women less than 40 years of age who underwent oopherectomy, to that in those who did not. The majority of patients who were offered oopherectomy were stage I and II disease (86\%), and $76 \%$ of them had mastectomy as surgical treatment modality. As adjuvant treatment $100 \%$ in oopherectomy group received hormonal therapy, $36 \%$ had radiation therapy and $24 \%$ had chemotherapy. No significant difference in survival between the two groups was determined using both univariate and multivariate analysis. Of further interest, the group of patients who did not receive oopherectomy lived longer than those who had bilateral oopherectomy (mean survival of 288 months vs. 264 months $\left(\log\right.$-rank $\left.p=0.215, X^{2}=1.54\right)$.

\section{Discussion}

Breast cancer in patients under 40 years of age is uncommon; however, it has generated considerable

Table 2 Cox proportional hazards model of survival in all patients

\begin{tabular}{lcccccc}
\hline Variable & B & SE & Wald & df & Sig. & Exp(B) \\
\hline Age at diagnosis & .019 & .012 & 2.661 & 1 & .103 & 1.019 \\
\hline Category & -.566 & .355 & 2.539 & 1 & .111 & .568 \\
\hline Tumour size & .022 & .007 & 8.981 & 1 & $.003^{*}$ & 1.022 \\
\hline Tumour grade & .097 & .095 & 1.027 & 1 & .311 & 1.101 \\
\hline Histological type & -.062 & .105 & .353 & 1 & .552 & .939 \\
\hline Tumour invasion & .009 & .159 & .003 & 1 & .956 & 1.009 \\
\hline Nodal status & .131 & .089 & 2.165 & 1 & .141 & 1.140 \\
\hline Distant metastasis & .107 & .272 & .154 & 1 & .695 & 1.113 \\
\hline ER receptors status & .039 & .036 & 1.161 & 1 & .281 & 1.040 \\
\hline PR receptors status & .119 & .051 & 5.351 & 1 & $.021^{*}$ & 1.126 \\
\hline HER2 status & -.090 & .056 & 2.591 & 1 & .107 & .914 \\
\hline Hormonal therapy & -.264 & .389 & .462 & 1 & .497 & .768 \\
\hline Chemotherapy & -.007 & .079 & .008 & 1 & .927 & .993 \\
\hline Radiotherapy & -.003 & .010 & .071 & 1 & .790 & .997 \\
\hline Surgical treatment & .011 & .209 & .003 & 1 & .957 & 1.011 \\
\hline The output of this anas & & & &
\end{tabular}

The output of this analysis includes the unstandardized regression coefficient (B), the standard error of B and its Wald test significance value, the degrees of freedom and the significance value of the coefficient. If the significance value for the coefficient is more than 0050 , then the co-variate effect cannot be assumed to be different from 0 . The predicted change in the hazard per unit increase in the co-variate is $\operatorname{Exp}(B)$; if the value is less than 1, then the direction of the effect is towards reducing the hazard rate. To be considered to have a significant effect on the hazard rate, the 95 per cent confidence interval for the $\operatorname{Exp}(B)$ should not include 1.

Category = less than 40 yrs group vs. more than 40 yrs group

$(*)$ = significant values.

$\mathrm{df}=$ degree of freedom

$B=$ unstandardized regression coefficient

$\operatorname{Exp}(B)=$ predicted change in the hazard per unit increase in the co-variate interest because of the associated unfavorable outcome reported in several studies $[6,7,13,14]$. Younger age has been generally accepted as an independent adverse prognostic indicator of survival in breast cancer [15-18]. Nevertheless, many reports suggest that the poor outcomes associated with this age group are complicated by several additional factors $[5,13,19]$. Given the lack of routine screening programmes for women younger than 40 years, it is not surprising that women in this age group are more likely to present with a palpable mass and that their tumours tends to be larger and are more likely to have nodal involvement, than tumours detected by screening $[5,13,20]$.

It has been determined that underlying tumour pathology such as higher tumour grade, nodal status and presence of distant metastasis at diagnosis contribute to the worse outcome in breast cancer in women less than 40 years of age $[4,5,21,22]$. In relation to receptor status, tumours in young women have been predominantly reported as ER and PR negative, and have also been shown to over-express Her2/neu [6,13,19,23,24]. In addition; the rates of the known aggressive triple negative (PR, ER and HER2 -ve) tumour, which carries high risk of recurrence, were reported to be higher in young females [25]. In this study, younger women had tumours that were distinctly different from those in older women and were characterized by previously identified unfavorable biological parameters. Histopathological analysis showed that the majority of younger women were diagnosed with high grade and advanced stage tumours. Invasive ductal carcinoma was common in both groups. Although rare in our cohort of patients, invasive lobular carcinoma was more common in older women, a finding similar to that published in the literature [26,27]. Furthermore, biological evaluation of breast cancer in young women group revealed higher frequency of ER negativity and HER2/neu overexpression. No significant difference was identified in PR status, although it should be noted that the majority of patients in both groups were PR positive (70\%). These findings strongly support accumulating evidence that breast cancer in young patients is biologically more aggressive and associated with unfavorable prognostic markers relative to their older counterparts.

The accumulating evidence of biologically unfavorable breast cancer among younger women has resulted in more aggressive treatment strategies for this patient population. Hence, there is a very low threshold towards more aggressive surgical treatment of breast cancer in young females. Although BCS has been found in some studies to be associated with higher rates of local recurrence after long term follow-up [28,29], numerous studies have failed to confirm the superiority of mastectomy over breast conserving surgery (BCS) in 
improving both the disease-free and overall survival. Of those is a recent report by Livi et al., who analysed the breast cancer outcome in 346 young females and found no significant role of surgical treatment (mastectomy $v s$. BCS) as predictor of local recurrence [22]. In this study, and in keeping with literature, although the majority of our young patients underwent mastectomy, we found no significant difference in local recurrence-free survival between the mastectomy and BCS groups.

The role of postoperative radiotherapy in reducing breast cancer local recurrence has been confirmed in many studies [30-34]. However; there is conflicting evidence in translating its role in controlling local recurrence into breast cancer mortality reduction $[30,33,35,36]$. Significant survival improvements have been reported in subgroup analyses of patients with favorable prognostic indicators like: grade I disease, less than 3 positive lymph nodes, tumours less than $2 \mathrm{~cm}$ and hormone receptors positive disease, but not in high risk groups [33,35,37-39]. Adjuvant chemotherapy has been shown to benefit young patients with approximately $37 \%$ reduction in recurrence rates and a $27 \%$ reduction in death rates $[40,41]$. With both single-agent chemotherapy and polychemotherapy, there is trend towards greater benefits among younger women, but both for recurrence and for mortality the age-standardized effect of single-agent regimens were significantly less favorable than those of the polychemotherapy regimens [42]. Regarding chemotherapeutic agents, it has been widely accepted that anthracyclines and taxanes are the most effective agents in adjuvant settings of breast cancer management in young females. A metaanalysis by the early breast cancer trialists' collaboration group (EBCTCG) showed that 6 months of anthracycline-based polychemotherapy reduces the annual breast cancer death by about $38 \%$ for women younger that 50 years of age at diagnosis [42].

Hormonal therapy effect had been considered of secondary importance in young females with breast cancer. However; it has become common current practice to follow adjuvant chemotherapy in receptor positive young women. This practice is based on the evidences provided by recent trials [42-46]. Hormonal therapy value in premenopausal women has been defined recently in a meta-analysis of randamised trials which showed that combination of chemotherapy with 5 years Tamoxifen in ER positive breast cancer reduce risk of death by $57 \%$ [42]. In addition, the intermediate results of the international breast cancer study group trial confirmed that Tamoxifen significantly improve outcome in premenopausal women with hormone receptors positive disease [44].

Therefore, in our cohort of patients, those less than 40 years of age were managed aggressively independent of the disease stage. Further elucidation of tumour characteristics such as HER2neu status has given adjuvant therapists the opportunity to tailor systemic treatment and clearly the younger patients are more suited to this treatment based on our and others findings

Previous reports comparing survival between women less than and greater than 40, with breast cancer have returned inconsistent results. Both Kollias et al. and Yildirim et al. found decreased DFS and OS in younger patients $[17,18]$. However; other studies have demonstrated that, young age in its own is not an adverse prognostic factor $[13,47]$. The small number of patients, study design and the employment of different statistical methods might explain these variations. Moreover, only a few studies have assessed the prognostic indicators in order to confirm whether the poorer outcome in younger women could be related to the biological characteristics of their tumours. By controlling for confounders and employing multivariate analysis methods, we have been unable to identify significant difference in both DFS and OS between the two groups of patients. Consistent with McAree et al [19], we identified PR receptor positivity as a predictor of survival in younger women with breast cancer. In additions; other variables like tumour size and stage were shown to influence OS while nodal status and adjuvant chemoendocrine therapy predicted DFS in women less than 40 by multivariate analysis. We have failed to identify any benefit of ovarian ablation in improving OS in younger women. Interestingly, the group of patients who received bilateral prophylactic oopherectomy had poorer OS than those who did not. This finding could be explained by the fact that most of our patients had adjuvant chemoendocrine therapy. EBCTCG overviews have shown that, although ovarian ablation is associated with improved survival for premenopausal women both on recurrence and on breast cancer mortality, the effect of ovarian treatment appear to be smaller in the trials where both groups got chemotherapy [42]. In addition, they reported that more breast cancer related deaths were noted in the trials of ovarian ablation in the presence of chemotherapy than in the trials of ablation in the absence of chemotherapy [48-50]. This could partially be explained by the toxic effect of chemotherapy on the ovary, limiting the benefits of other ovarian treatments.

\section{Conclusions}

This study has demonstrated that women less than 40 years of age present with higher grade and poorly differentiated tumours. Moreover; younger women had tumours that were more likely to be ER negative and HER2/neu receptor over-expressed. However; we have shown no difference in both disease-free survival and 
over-all survival between this group of patients and women over 40 years of age.

\section{Acknowledgements}

We would like to thank the National Breast Cancer Research Institute (NBCRI) for their financial support of the study.

\section{Author details}

'Department of Surgery, National University of Ireland, Galway, Ireland.

${ }^{2}$ Biostatistics Unit, National University of Ireland, Galway, Ireland.

\section{Authors' contributions}

EAHK designed the study, was responsible for data analyses and drafted the manuscript. JMEB and CC contributed to data collation. RWG contributed to manuscript editing. CD contributed to statistical analysis of the survival data. KJS and MJK conceived and designed the study, critically reviewed the manuscript and participated clinically. All authors read and approved the final manuscript.

\section{Competing interests}

The authors declare that they have no competing interests.

Received: 22 September 2010 Accepted: 28 August 2011 Published: 28 August 2011

\section{References}

1. Parkin DM, Bray F, Ferlay J, Pisani P: Global cancer statistics, 2002. Ca-a Cancer Journal for Clinicians 2005, 55(2):74-108.

2. Swanson GM, Lin CS: Survival patterns among younger women with breast cancer: the effects of age, race, stage, and treatment. J Natl Cancer Inst Monogr 1994, 16:69-77.

3. Brinton LA, Sherman ME, Carreon JD, Anderson WF: Recent Trends in Breast Cancer Among Younger Women in the United States. Journal of the National Cancer Institute 2008, 100(22):1643-1648.

4. Chung M, Chang HR, Bland KI, Wanebo HJ: Younger women with breast carcinoma have a poorer prognosis than older women. Cancer 1996, 77(1):97-103.

5. Sidoni A, Cavaliere A, Bellezza G, Scheibel M, Bucciarelli E: Breast cancer in young women: clinicopathological features and biological specificity. Breast 2003, 12(4):247-250.

6. Gnerlich JL, Deshpande AD, Jeffe DB, Sweet A, White N, Margenthaler JA: Elevated Breast Cancer Mortality in Women Younger than Age 40 Years Compared with Older Women Is Attributed to Poorer Survival in EarlyStage Disease. Journal of the American College of Surgeons 2009, 208(3):341-347.

7. Fredholm H, Eaker S, Frisell J, Holmberg L, Fredriksson I, Lindman H: Breast Cancer in Young Women: Poor Survival Despite Intensive Treatment. PLoS One 2009, 4(11):A38-A46.

8. Gajdos C, Tartter PI, Bleiweiss IJ, Bodian C, Brower ST: Stage 0 to stage III breast cancer in young women. Journal of the American College of Surgeons 2000, 190(5):523-529.

9. Maggard MA, O'Connell JB, Lane KE, Liu JH, Etzioni DA, Ko CY: Do young breast cancer patients have worse outcomes? Journal of Surgical Research 2003, 113(1):109-113.

10. Kimura M, Yanagita Y, Fujisawa T, Koida T: Study of time-course changes in annual recurrence rates for breast cancer: Data analysis of 2,209 patients for 10 years post-surgery. Breast Cancer Research and Treatment 2007, 106(3):407-411.

11. Daniel SR, Armstrong K, Silber JH, Rosenbaum PR: An Algorithm for Optimal Tapered Matching, With Application to Disparities in Survival. Journal of Computational and Graphical Statistics 2008, 17(4):914-924.

12. R Development Core Team: R: A Language and Environment for Statistical Computing. Vienna, Austria: R Foundation for Statistical computing; 2008.

13. Bharat A, Aft RL, Gao F, Margenthaler JA: Patient and Tumor Characteristics Associated With Increased Mortality in Young Women (< $=40$ Years) With Breast Cancer. Journal of Surgical Oncology 2009, 100(3):248-251.
14. Foo CS, Su D, Chong CK, Chng HC, Tay KH, Low SC, Tan SM: Breast cancer in young Asian women: Study on survival. Anz Journal of Surgery 2005, 75(7):566-572.

15. Bonnier P, Romain S, Charpin C, Lejeune C, Tubiana N, Martin PM, Piana L: Age as a Prognostic Factor in Breast-Cancer - Relationship to Pathological and Biologic Features. International Journal of Cancer 1995, 62(2):138-144.

16. Xiong QH, Valero V, Kau V, Kau SW, Taylor S, Smith TL, Smith TL, Buzdar AU, Hortobagyi GN, Theriault RL: Female patients with breast carcinoma age 30 years and younger have a poor prognosis - The M. D. Anderson Cancer Center Experience. Cancer 2001, 92(10):2523-2528.

17. Kollias J, Elston CW, Ellis IO, Robertson JFR, Blamey RW: Early-onset breast cancer - Histopathological and prognostic considerations. British Journal of Cancer 1997, 75(9):1318-1323.

18. Yildirim E, Dalgic T, Berberoglu U: Prognostic significance of young age in breast cancer. Journal of Surgical Oncology 2000, 74(4):267-272.

19. McAree B, O'Donnell ME, Spence A, Lioe TF, McManus DT, Spence RA: Breast cancer in women under 40 years of age: a series of 57 cases from Northern Ireland. Breast 2010, 19(2):97-104.

20. Leung GM, Thach TQ, Lam TH, Hedley AJ, Fielding R, Yip PSF, Lau EMC, Wong CM: Trends in breast cancer incidence in Hong Kong between 1973 and 1999: an age-period-cohort analysis. British Journal of Cancer 2002, 87(9):982-988.

21. Feldman AL, Welch JP: Long-term outcome in women less than 30 years of age with breast cancer. Journal of Surgical Oncology 1998, 68(3):193-198.

22. Livi L, Meattini I, Saieva C, Borghesi S, Scotti V, Petrucci A, Rampini A, Marrazzo L, Di Cataldo V, Bianchi S, et al: The impact of young age on breast cancer outcome. Eur J Surg Oncol 2010.

23. Vrieling C, Collette L, Fourquet A, Hoogenraad WJ, Horiot JC, Jager JJ, Oei SB, Peterse HL, Pierart M, Poortmans PM, et al: Can patient-, treatmentand pathology-related characteristics explain the high local recurrence rate following breast-conserving therapy in young patients? European Journal of Cancer 2003, 39(7):932-944.

24. Colleoni M, Rotmensz N, Robertson C, Orlando L, Viale G, Renne G, Luini A, Veronesi $P$, Intra $M$, Orecchia $R$, et al: Very young women $(<35$ years) with operable breast cancer: features of disease at presentation. Annals of Oncology 2002, 13(2):273-279.

25. Rakha EA, Reis-Filho JS, Ellis IO: Basal-like breast cancer: a critical review. Journal of Clinical Oncology 2008, 26(15):2568-2581.

26. Kwong A, Cheung P, Chan S, Lau S: Breast Cancer in Chinese Women Younger than Age 40: Are They Different from Their Older Counterparts? World Journal of Surgery 2008, 32(12):2554-2561.

27. Cristofanilli M, Gonzalez-Angulo A, Sneige N, Kau SW, Broglio K, Theriault RL, Valero V, Buzdar AU, Kuerer H, Buccholz TA, et al: Invasive lobular carcinoma classic type: Response to primary chemotherapy and survival outcomes. Journal of Clinical Oncology 2005, 23(1):41-48.

28. van Nes JG, van de Velde CJ: The preferred treatment for young women with breast cancer-mastectomy versus breast conservation. Braest 2006 15(Suppl 2):S3-10

29. Zhou P, Gautam S, Recht A: Factors affecting outcome for young women with early stage invasive breast cancer treated with breast-conserving therapy. Breast Cancer Research and Treatment 2007, 101(1):51-57.

30. EBCTCG: Favourable and unfavourable effects on long-term survival of radiotherapy for early breast cancer: an overview of the randomised trials. Lancet 2000, 355(9217):1757-1770

31. Clarke M, Collins R, Darby S, Davies C, Elphinstone P, Evans E, Godwin J, Gray R, Hicks C, James S, et al: Effects of radiotherapy and of differences in the extent of surgery for early breast cancer on local recurrence and 15-year survival: an overview of the randomised trials. Lancet 2005, 366(9503):2087-2106.

32. Masinghe SP, Faluyi $\mathrm{OO}$, Kerr GR, Kunkler IH: Breast radiotherapy for occult breast cancer with axillary nodal metastases-does it reduce the local recurrence rate and increase overall survival? Clinical Oncology 2011, 23(2):95-100.

33. Yang PS, Chen CM, Liu MC, Jian JM, Horng CF, Liu MJ, Yu BL, Lee MY, Chi CW: Radiotherapy can decrease locoregional recurrence and increase survival in mastectomy patients with T1 to T2 breast cancer and one to three positive nodes with negative estrogen receptor and positive lymphovascular invasion status. Int I Radiat Oncol Biol Phys 2009, 77(2):516-522. 
34. Kunkler $\mathbb{H}$, Williams $\sqcup$, King $C$, Jack W: Breast radiotherapy: considerations in older patients. Clinical Oncology 2009, 21(2):111-117.

35. Kyndi M, Overgaard M, Nielsen HM, Sørensen FB, Knudsen H, Overgaard J: High local recurrence risk is not associated with large survival reduction after postmastectomy radiotherapy in high-risk breast cancer: a subgroup analysis of DBCG 82 b\&c. Radiother Oncol 2009, 90(1):74-79.

36. Overgaard $\mathrm{M}$ : Overview of randomized trials in high risk breast cancer patients treated with adjuvant systemic therapy with or without postmastectomy irradiation. Semin Radiat Oncol 1999, 9(3):292-299.

37. Overgaard M, Nielsen HM, Overgaard J: Is the benefit of postmastectomy irradiation limited to patients with four or more positive nodes, as recommended in international consensus reports? A subgroup analysis of the DBCG 82 b\&c randomized trials. Radiother Oncol 2007, 82(3):247-253.

38. Whelan T, Levine M: More evidence that locoregional radiation therapy improves survival: what should we do? J Natl Cancer Inst Monogr 2005, 97(2):82-84.

39. Ragaz J, Olivotto IA, Spinelli JJ, Phillips N, Jackson SM, Wilson KS, Knowling MA, Coppin CM, Weir L, Gelmon K, et al: Locoregional radiation therapy in patients with high-risk breast cancer receiving adjuvant chemotherapy: 20-year results of the British Columbia randomized trial. J Natl Cancer Inst Monogr 2005, 97(2):116-126.

40. Menard S, Casalini P, Cascinelli N, Balsari A: Breast carcinoma in young patients. Lancet 2000, 356(9235):1113-1113.

41. Abe O, Abe R, Enomoto K, Kikuchi K, Koyama H, Nomura Y, Sakai K, Sugimachi K, Tominaga T, Uchino J, et al: Polychemotherapy for early breast cancer: an overview of the randomised trials. Lancet 1998, 352(9132):930-942.

42. EBCTCG: Effects of chemotherapy and hormonal therapy for early breast cancer on recurrence and 15-year survival: an overview of the randomised trials. Lancet 2005, 365(9472):1687-1717.

43. Andersson M, Kamby $C$, Jensen MB, Mouridsen $H$, Ejlertsen $B$, Dombernowsky P, Rose C, Cold S, Overgaard M, Andersen J, et al: Tamoxifen in high-risk premenopausal women with primary breast cancer receiving adjuvant chemotherapy. Report from the Danish Breast Cancer Co-Operative Group DBCG 82B trial. European Journal of Cancer 1999, 35(12):1659-1666.

44. Colleoni M, Gelber S, Goldhirsch A, Aebi S, Castiglione-Gertsch M, Price KN, Coates AS, Gelber RD: Tamoxifen after adjuvant chemotherapy for premenopausal women with lymph node-positive breast cancer: International Breast Cancer Study Group Trial 13-93. Journal of Clinical Oncology 2006, 24(9):1332-1341.

45. Morales L, Canney P, Dyczka J, Rutgers E, Coleman R, Cufer T, WelnickaJaskiewicz M, Nortier J, Bogaerts J, Therasse P, et al: Postoperative adjuvant chemotherapy followed by adjuvant tamoxifen versus nil for patients with operable breast cancer: A randomised phase III trial of the European Organisation for Research and Treatment of Cancer Breast Group. European Journal of Cancer 2007, 43(2):331-340.

46. Margolin KA, Liu PY, Unger JM, Fletcher WS, Flaherty LE, Urba WJ, Hersh EM, Hutchins LE, Sosman JA, Smith JW, et al: Phase II trial of biochemotherapy with interferon alpha, dacarbazine, cisplatin and tamoxifen in metastatic melanoma: a Southwest Oncology Group trial. Journal of Cancer Research and Clinical Oncology 1999, 125(5):292-296.

47. Anderson BO, Senie RT, Vetto JT, Wong GY, McCormick B, Borgen PI: Improved Survival in Young-Women with Breast-Cancer. Annals of Surgical Oncology 1995, 2(5):407-415.

48. Pritchard Kl: Adjuvant therapy of the very young woman. Breast 2007, 16: S136-S146.

49. Abe O, Abe R, Asaishi K, Enomoto K, Hattori T, Ino Y, Kikuchi K, Koyama H, Sawa K, Uchino J, et al: Systemic Treatment of Early Breast-Cancer by Hormonal, Cytotoxic, or Immune Therapy - 133 Randomized Trials Involving 31000 Recurrences and 24000 Deaths among 75000 Women .2. Lancet 1992, 339(8785):71-85.

50. Chia S, Bryce C, Gelmon K: The 2000 EBCTCG overview: a widening gap. Lancet 2005, 365(9472):1665-1666.

\section{Pre-publication history}

The pre-publication history for this paper can be accessed here:

http://www.biomedcentral.com/1471-2407/11/383/prepub

\section{doi:10.1186/1471-2407-11-383}

Cite this article as: Kheirelseid et al:: Younger age as a prognostic indicator in breast cancer: A cohort study. BMC Cancer 2011 11:383.

\section{Submit your next manuscript to BioMed Central and take full advantage of:}

- Convenient online submission

- Thorough peer review

- No space constraints or color figure charges

- Immediate publication on acceptance

- Inclusion in PubMed, CAS, Scopus and Google Scholar

- Research which is freely available for redistribution 